\title{
PATTERN OF PORE DEVELOPMENT IN THE COURSE OF MANUFACTURING ACTIVATED CARBON BY GAS ACTIVATION*
}

\author{
Hiroshi YANAI, Hiroshi TAKAHASHI \\ AND KEIICHI ISHIYAMA** \\ Department of Chemical Engineering, Muroran Institute of \\ Technology, Muroran, Japan
}

\begin{abstract}
The activation of various chars by $\mathrm{CO}_{2}$ gas was carried out. Experimental results are summarized as follows. The pores of activated carbon are formed in two steps. In the first step the content of residual volatile matter in the chars has an important influence on the pattern of development of the micropore and in the second step the macropore volume caused by raw materials and/or their subsequent history of heat treatment is the important influence. The more volatile matter a char contains, the higher the reactivity it exhibits, and the faster the rate of micropore growth. Also, the higher the degree of macropore development in the first step, the more it contributes to micropore formation in the subsequent course of gas activation.
\end{abstract}

\section{Introduction}

Previous investigations of gas activation reactions have dealt almost exclusively with devolatized chars or graphitized carbons that do not have an internal surface, because it is more convenient in handling the gas-solid reaction theoretically $y^{1,2,3,4)}$. In the industrial production of activated carbon, however, raw materials containing some residual volatile matter and ash are usually used. Accordingly, the activation reaction becomes extremely complicated.

The residual volatile matter should have a significant effect on the properties of resulting products, as already pointed out in the empirical work. ${ }^{5)}$ The macropore volume of raw materials should also affect micropore development. Concerning those subjects, however, there has been no full discussion on the basis of experiment or theory. This paper will discuss experimentally the effects of the residual volatile matter and macropore volume of raw material on the pore development pattern in the gas activation of carbon.

\section{Experimental Apparatus and Procedure}

The carbonizing procedure for preparing various chars was as follows. The material was charged into a retort encircled by an electric furnace and $\mathrm{N}_{2}$ gas was introduced at a certain flow rate to the retort until it

* Received on September 8, 1972

Presented at the 23th Annual Meeting of the Chem. Soc. of Japan, April 2, 1970 and the 24th Annual Meeting of the Chem. Soc. of Japan, April 2, 1971

** Kobe Steelworks, Inc., Kobe, Japan

干050 室蘭市水元町27-1

室蘭工業大学化学工学科 柳井 弘 reached the desired carbonizing temperature. The rising rate of temperature of the retort was regulated at $5^{\circ} \mathrm{G} / \mathrm{min}$.

Then the flow rate of $\mathrm{N}_{2}$ gas was kept at $0.2 \mathrm{l} / \mathrm{min}$ for $2 \mathrm{hrs}$ as a carbonizing period. Thus, various chars containing different quantities of residual volatile matter could be obtained by varying the carbonizing temperature between $300^{\circ} \mathrm{C}$ and $900^{\circ} \mathrm{C}$. The materials carbonized in this experiment were sawdust and barkdust of needle leaf tree (soft wood). Other commercial products such as Black charred acacia and so on were also prepared. The raw materials and their heat treating conditions are listed in Table 1.

The chars were dried at $105^{\circ} \mathrm{C}$ for $24 \mathrm{hrs}$, and then were put into the reaction tube, in which the temperature had been kept constant. $\mathrm{CO}_{2}$ gas was used as the activation gas and its flow rate was kept at 500-520 $\mathrm{ml} /$ min. The schematic diagram of the activation apparatus used, which is similar to the carbonizing one, is shown in Fig. 1. The reaction tube is made of silica, being $3.5 \mathrm{~cm}$ in diameter and $1 \mathrm{~m}$ in length.

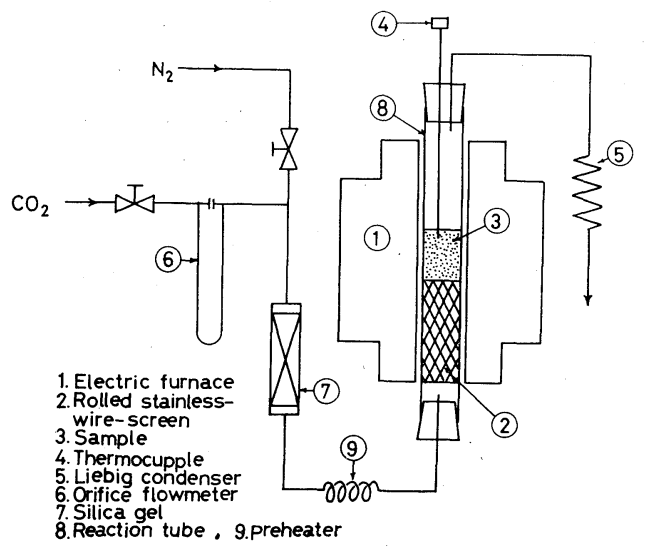

Fig. 1 Experimental apparatus for the activation 


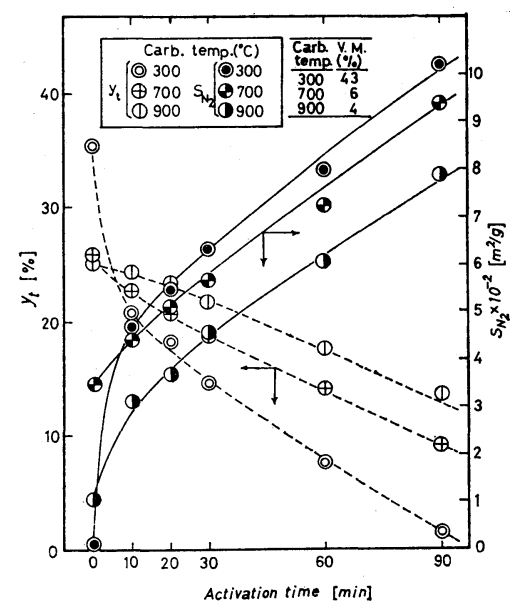

Fig. 2 Effect of activation time and carbonization temp. on the total yield and specific surface area, activation temp. $900^{\circ} \mathrm{C}, \mathrm{N}$-sawdust

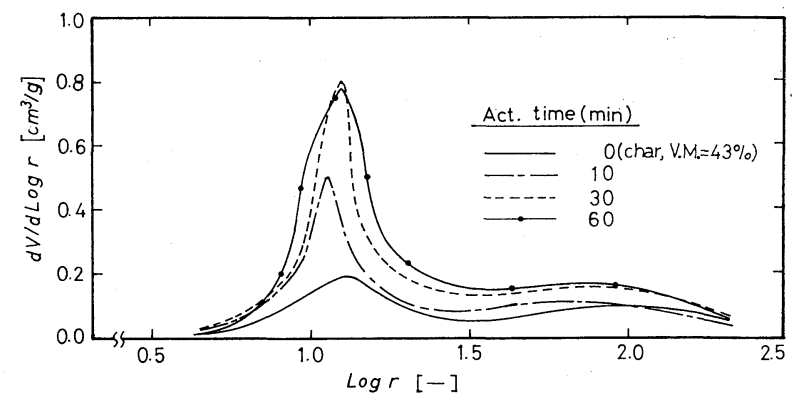

Fig. 3 Micropore distribution, carbonization temp. $300^{\circ} \mathrm{C}$, V.M. 43 wt $\%$, activation temp. $900^{\circ} \mathrm{C}, \mathbf{N}$-sawdust

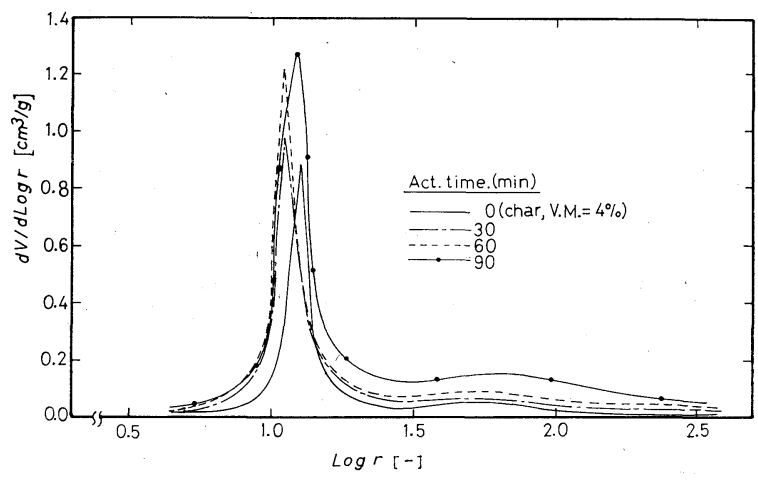

Fig. 4 Micropore distribution, carbonization temp. $900^{\circ} \mathrm{C}$, V.M. 4 wt $\%$, activation temp. $900^{\circ} \mathrm{C}, \mathrm{N}$-sawdust

Yield (or burn-off), volatile matter, ash, specific surface area, pore-siże distribution, true density and apparent density of both the chars and the activated products were determined in the experiment. The value of specific surface area was evaluated by the modified technique of the B. E. T. procedure. The micropore distribution was calculated by the application of the Kelvin equation based on the adsorption isotherm of water vapor, and the transitional-pore distribution and macropore distribution were determined by means of the mercury porosimeter. For the degassed sample, the value of true density was determined by pycnometer, and the apparent density was calculated by assuming that the apparent volume is equal to the volume of the mercury excluded by the sample under atmospheric pressure. Defining the inner pore
Table 1 Source materials and their heat-treating conditions

\begin{tabular}{|c|c|c|c|}
\hline Material & Shape or size & $\begin{array}{c}\text { Carbonization } \\
\text { temperature } \\
{\left[{ }^{\circ} \mathrm{C}\right]}\end{array}$ & $\begin{array}{c}\text { Activation } \\
\text { temperature } \\
{\left[{ }^{\circ} \mathrm{C}\right]}\end{array}$ \\
\hline $\begin{array}{l}\mathrm{N}-*_{\text {sawdust }} \\
\text { Sawdust of } \\
\text { needle leaf } \\
\text { tree }\end{array}$ & 24-48 mesh & $\begin{array}{l}300 \\
500 \\
700 \\
900\end{array}$ & 900 \\
\hline N-barkdust & 24-48 mesh & 700 & $\begin{array}{l}750 \\
800 \\
850\end{array}$ \\
\hline $\begin{array}{l}\text { Black charred } \\
\text { acacia }\end{array}$ & cylindrical & - & 900 \\
\hline $\begin{array}{l}\text { Black charred } \\
\text { Japanese oak }\end{array}$ & cylindrical & - & 900 \\
\hline $\begin{array}{l}\text { Black charred } \\
\text { binderless } \\
\text { briquetted } \\
\text { N-sawdust }\end{array}$ & cylindrical & $\begin{array}{c}\text { electric } \\
\text { resistance } \\
106 \Omega \\
10^{7} \Omega \\
10^{8} \Omega\end{array}$ & 900 \\
\hline $\begin{array}{l}\text { Black charred } \\
\text { coconut shell }\end{array}$ & flat board & - & 900 \\
\hline $\begin{array}{l}\text { White charred } \\
\text { oak }\end{array}$ & cylindrical & $1,000-2,000$ & 900 \\
\hline
\end{tabular}

volume and apparent volume of porous solid as $V_{i}$ and $V_{l}$, respectively, the values of $V_{i} / V_{l}$ are given by

$$
V_{i} / V_{l}=\left(V_{i} / W_{s}\right) /\left(V_{l} / W_{s}\right)=\rho_{a}\left(1 / \rho_{a}-1 / \rho_{t}\right)
$$

\section{Experimental Results and Discussion}

\section{1 The first step of gas activation}

The changes of yield $y_{t}$ and specific surface area $S_{\mathrm{N}_{2}}$ with the progress of the activation are shown in Fig. 2. The effect of the content of residual volatile matter on $y_{t}$ or $S_{\mathrm{N}_{2}}$ at activation temperature of $900^{\circ} \mathrm{C}$ is illustrated. Figs. 3 and 4 show the changes of micropore distribution with the progress of the activation. In Fig. 3, the char containing 43 weight percent of volatile matter was activated, while in Fig. 4 , the ratio of volatile matter to the char was 4 percent.

Let us consider the period of 10 minutes from the beginning of activation as the first step of the activation process. In the activation of the char carbonized at $300^{\circ} \mathrm{C}$, which contains the larger quantity of volatile matter because of the low carbonizing temperature, the yield decreases rapidly and $S_{\mathrm{N}_{2}}$, on the contrary, increases rapidly during this first step. This is the reason that the char is suddenly exposed to the high temperature of $900^{\circ} \mathrm{C}$ and the volatile matter is rapidly and violently evaporated in this stage. This suggests a high development of macropores in this period. Activating gas can penetrate easily into the resulting macropores, and therefore micropores in and around those macropores are formed.

When the char is carbonized at the high temperature 
of $700^{\circ} \mathrm{C}$ or $900^{\circ} \mathrm{C}$, residual volatile matter is almost evaporated and crystallization of carbon should occur considerably, and therefore the production of a large quantity of macropores, cannot be expected in the first step.

Because an activating gas pops in and out of a macropore and a micropore, the place near the entrance of the pores is more excessively eroded by the reaction than the inner portions. Hence, the structure of the pores assumes a bell-shaped form. The more frequently the activating gas pops in and out of the pores, the more distinctly should the bell-shape form, and it leads to the large dispersion of pore-distribution curve. Carbon possessing more macropores can be expected to show a larger dispersion of macropore- or micropore- distribution curve. Comparison between Fig. 3 and Fig. 4 gives evidence of this deduction.

On the basis of Figs. 3 and 4, the effect of the properties of the char on the rate of oxidation can be discussed, taking note of the increasing rate of micropore volume with the progress of the activation. In the first step of the activation, the amorphous carbon of a nascent state appears with the evaporation of the residual volatile matter of the char. The rate of oxidation can be highly promoted in such a condition if the oxidizing gas can easily reach the interior of the solid through pores. This is the reason for the rapid increase of micropore volume in the first step, as seen in Fig. 3. The char carbonized at $900^{\circ} \mathrm{C}$ has two properties resulting from high carbonizing temperature: First, the char contains less volatile matter. Second, the carbon is considerably crystallized, i. e., the micropore structure is considerably developed during carbonization. Carbons being in the nascent state almost cannot be produced from the first property. It is most difficult for the oxidizing gas to penetrate into the interior of the solid and to react with carbon from the second property. Therefore, the rate of the reaction decreases and micropore volume does not increase so much, as shown in Fig. 4.

The first step also covers the preferential oxidation of residual carbon-rich hydrocarbon closing the pores produced by carbonization. Blocking of the pores is caused by the solidification of the carbon-rich hydrocarbon at room temperature after caibonization. This is one of the most reasonable clues to explain the mechanism of the rapid increase of $S_{\mathrm{N}_{2}}$ in careful comparison with a little decrease of $y_{t}$ in the char carbonized at the temperature of $900^{\circ} \mathrm{C}$, as shown in Fig. 2.

\section{2 The second step of gas activation}

Various carbons made from different raw materials or various chars prepared in different carbonizing conditions were activated to investigate the second step. The chars are different in macropore structure and volume.

The developing patterns of pore structure with the progress of activation for the black char of oak and white char of oak are shown in Figs. 5 and 6. The white char of oak contains almost no volatile matter in cont-

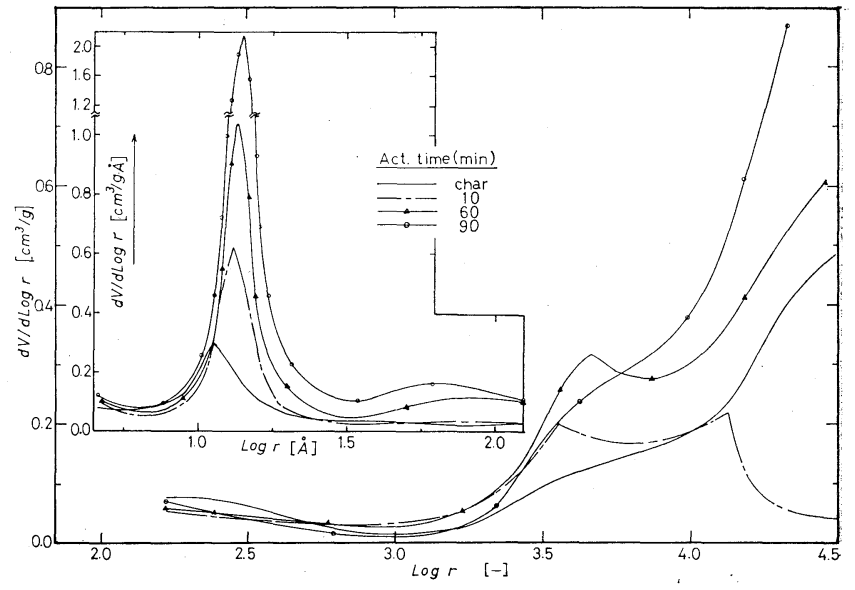

Fig. 5 Changes of the micropore and macropore distributions with the progress of the activation, Black charred Japanese oak

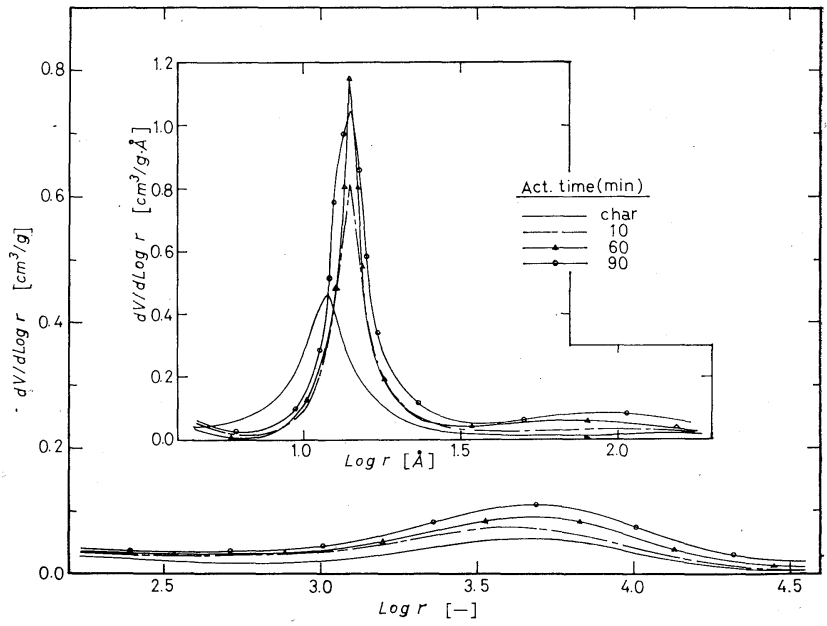

Fig. 6 Changes of the micropore and macropore distributions with the progress of the activation, White charred oak

rast to the black char of oak, because it is carbonized at a high temperature above $1000^{\circ} \mathrm{C}$. Every peak of the micropore distribution curves shifts towards the larger radius with the progress of the activation. This tendency is remarkable for the char containing the higher volatile matter, because of high development of the bell-shaped macropore in the first step of the activation.

The variation of $V_{i} / V_{l}$ with burn-off is shown in Fig. 7. The relationship between $V_{m a}$ and $V_{m i}$ during the activation period is shown in Fig. 8. The burn-off is evaluated from the yield relating to the oxidation reaction by $\mathrm{CO}_{2}$ gas in the second step, assuming the quantity of volatile matter to be constant. Thus,

$$
\text { Burn-off (B.O.) }=1-\frac{W_{t}}{W_{10}}=1-\frac{W_{t} / W_{0}}{W_{10} / W_{0}}=1-\frac{y_{a}}{y_{a, 10}}
$$

where $y_{a, 10}$ and $y_{a}$ are the activation yields after $10 \mathrm{~min}$ and an arbitrary time from the beginning of the activation, respectively. In Fig. 7, therefore, B.O.=zero corresponds to the time $10 \mathrm{~min}$ from the beginning. It can be said from the values listed in Fig. 7 that the larger the ratio of inner volume to lump volume $V_{i} / V_{l}$, the more highly the region of macropore develops. The macropore volume per unit mass of active carbon 


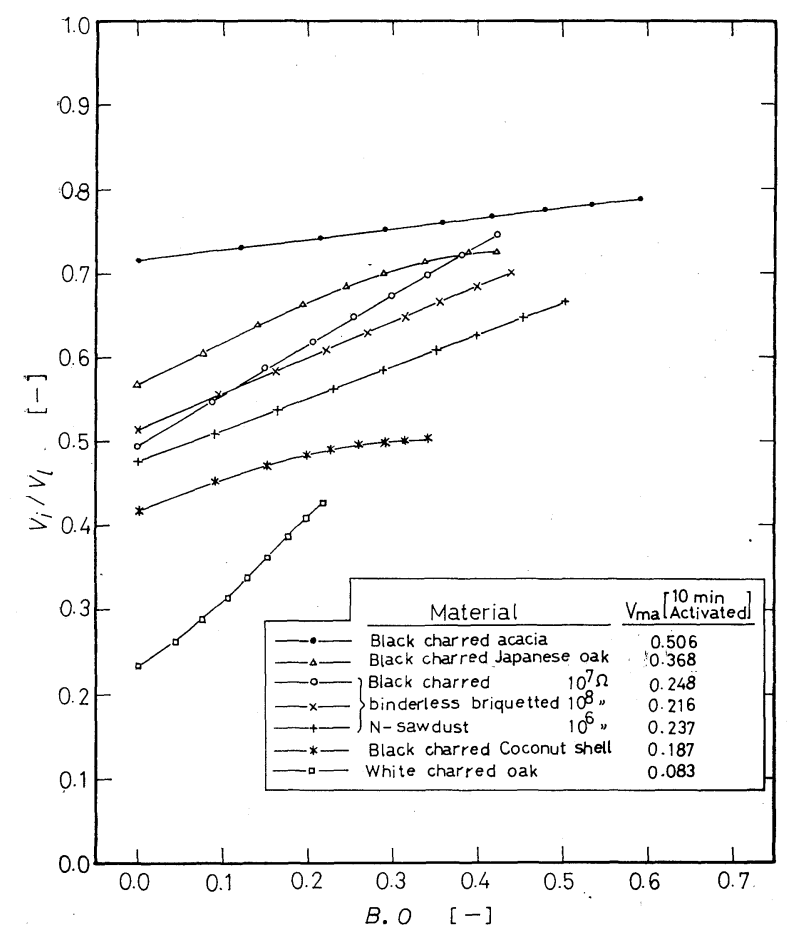

Fig. 7 Relationship between burn-oIf and the ratio of i izaer volume to lump volume

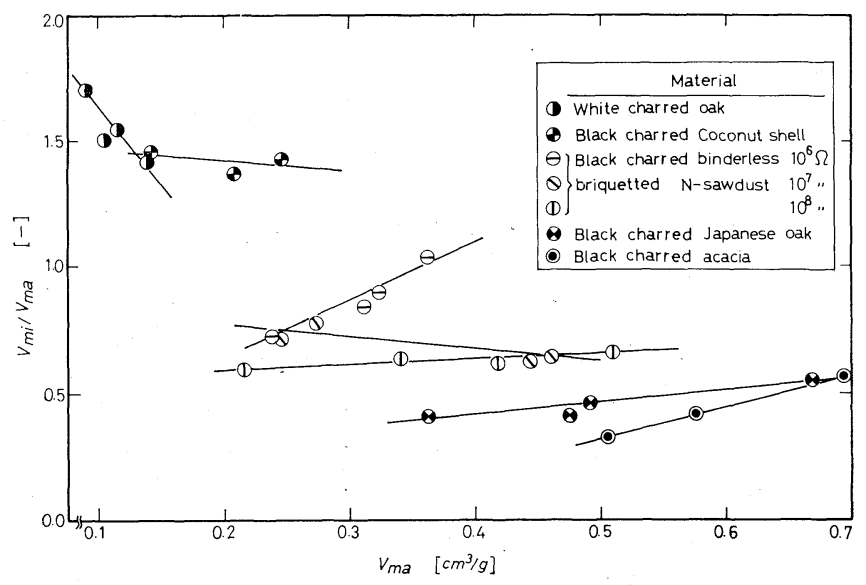

Fig. 8 Relationship between macropore volume and the ratio of micropore volume to macropore volume

is considered to increase with the progresss of activation because the value of $V_{i} / V_{l}$ increases with burn-off. Fig. 8 shows how the micropore volume changes during activation. The value of $V_{m i} / V_{m a}$ increases regularly with the value of $V_{m a}$, that is, with the progress of activation, for all the materials except "white charred oak". The white charred oak shows a preferential development of the macropore in comparison with the micropore. The reason is that the white charred oak contains almost no macropore, and the oxidizing gas cannot penetrate deeply into the interior through the macropore. Thus, the macropore can be concluded to play an important role as the avenue or channel of the oxidizing gas in the second step of activation.

The increase of the ratio $V_{i} / V_{l}$ with the advance of burn-off in Fig. 7 means that the oxidation reaction takes place more violently in the interior of the porous solid than on the external surface. The gas-activation reaction of carbon, therefore, is suggested to follow the "zone reaction model" inclining towards the "homogeneous reaction model".

\section{Conclusion}

A model of pore development comprising first and second steps was proposed to explain the course of manufacturing active carbon by means of gas activation. In the first step the content of residual volatile matter in the chars, and in the second step the macropore volume caused by raw materials and/or their subsequent history of heat treatment, affect the developing pattern of micropore of active carbon.

The first step: (1) The pores are formed by the thermal decomposition of volatile matter, and at the same time reactive amorphous carbon is generated. Bellshape pores are produced.

(2) The preferential oxidation of the residual carbonrich hydrocarbon opens the closed pores produced in the carbonization.

The amorphous carbon of the nascent state reacts selectively with the oxidizing gas. The more volatile matter it contains, the higher the reactivity it exhibits, and the rate of micropore development becomes faster.

The second step: (1) The oxidizing gas diffuses through macropores of the bell-shaped form and reacts with carbon. (2) Micropore is mainly developed.

When the macropore is more developed in the earlier stage of activation, it contributes more to micropore formation in the subsequent course of activation.

\section{Nomenclature}

\begin{tabular}{|c|c|}
\hline$r$ & $=$ pore radius \\
\hline$S_{\mathrm{N}_{2}}$ & $\begin{array}{l}=\text { B.E.T. specific surface area measured by } \\
\text { nitrogen adsorption }\end{array}$ \\
\hline$V, V_{i}$ & $=$ pore volume or inner pore volume \\
\hline & $=$ lump volume or apparent volume \\
\hline V.M. & $\begin{aligned}= & \text { volatile matter of char, } \\
& (\text { weight of volatile matter }) \times 100 /(\text { weight of char })[w t \%\end{aligned}$ \\
\hline$V_{m a}$ & $=$ macropore volume \\
\hline$V_{m i}$ & $=$ micropore volume \\
\hline$W_{0}$ & $=$ weight of char (i.e., carbonized material) \\
\hline$W_{R}$ & $=$ weight of raw material prepared for carbonization \\
\hline$W_{s}$ & $=$ weight of solid \\
\hline$W_{10}$ & $=$ weight of active carbon activated for $10 \mathrm{~min}$ \\
\hline$W_{t}$ & $=$ weight of active carbon activate \\
\hline$y_{a}$ & $=$ activation yield, $W_{t} / W_{0}$ \\
\hline$y_{a, 10}$ & $=$ activation yield, $W_{10} / W_{0}$ \\
\hline$y_{c}$ & $=$ carbonization yield, $W_{0} / W_{R}$ \\
\hline$y_{t}$ & $=$ total yield, $y_{a} y_{c}=W_{t} / W_{R}$ \\
\hline$\rho_{a}$ & $=$ \\
\hline & $=$ true density \\
\hline
\end{tabular}

\section{Literature Cited}

1) Ishida, M. and C. Y. Wen: AIChE J., 14, 311 (1968)

2) Kawahata, M. and P. L. Walker, Jr: Proc. 5th Carbon Conference, Pergamon, London (1962)

3) idem: Proc. Anthracite Conf., Mineral Industries Experimenta Station, the Pennsylvania State University, Bulletin No. 75, p. $63(1961)$

4) Petersen, E. E.: AIChE J., 3, 443 (1957)

5) Yanai, H.: Kagaku Kōgaku (Chem. Eng., Japan), 26, 518 (1962) 